\title{
Implementation And Optimization System ERP In Inventory Control
}

\author{
Barbara Laenna Encarnação De Moura ${ }^{1}$, Glaudia Taj Pinheiro Dos Santos ${ }^{1}$, Tatiana Fideles Da Silva1
}

${ }^{1,2}$ Centro Universitário do Norte - UNINORTE. Av. Joaquim Nabuco, 1469, Centro Manaus-Amazonas-Brasil. CEP: 69005-290. Fone: +55 (92) 3212-5000. (barbara_laenna@ hotmail.com, glaudiataj@gmail.com, tati_jesiel@ hotmail.com

\begin{abstract}
In the context of global business competition for survival of a company, is necessary a maximum productivity and improvement of its processes, using it resources with the help of technologies from the ERP system. The article aims to assess the impacts of the shares in the studied company productivity, improving its performance. The methodologies and techniques used were made through a case study conducted by a research in JB Andaimes company, through questionnaires, interviews and direct observations. The results and analyzes helped on optimizing the inventory management process, reducing costs, better managing the materials and increasing demand for its products, strategically contributing to the decision-making.
\end{abstract}

Keywords: Business Competitiveness: Technologies, Optimization, Inventory Management System ERP.

\section{Implementação e Otimização do Sistema ERP no Controle do Estoque}

\section{RESUMO}

No contexto global de competitividade corporativa para sobrevivência de uma empresa, é necessário produtividade e aperfeiçoamento ao máximo de seus processos, auferido com mais apreço dos seus capitais através do hábito de conhecimento do sistema ERP. O artigo tem como propósito prognosticar os impactos das ações da produtividade na empresa estudada, melhorando sua performance. Os métodos e técnicas utilizadas foram realizados através de um estudo de caso efetuado na empresa JB Andaimes, por intermédio de questionários, entrevistas e observações diretas. Os resultados obtidos e suas análises influenciaram na otimização do método de administração de estoque, reduzindo os custos, administrando melhor os materiais e aumentando a demanda de seus produtos, auxiliando taticamente para as tomadas de decisões.

Palavras Chaves: Competitividade Empresarial: Tecnologias, Otimização, Sistema de Gestão de Estoque ERP.

\section{INTRODUÇÃO}

Na esfera atual do processo logístico, as corporações necessitam desenvolver seu potencial competitivo no âmbito global, por meio de análise das etapas planejada otimizando seus seguimentos na produção. Planejar é entender como a consideração conjunta da situação presente e da visão de futuro influencia as decisões tomadas no presente para que se atinjam determinados objetivos no futuro [1]. Aumentando assim, seu conhecimento operacional e gerencial, como plano tático para as tomadas de decisões, correspondendo às disputas do ramo do negócio em continua mudança.

Desse modo, para que uma empresa seja bem sucedida, a estratégia logística e a estratégia competitiva devem estar alinhadas, ou seja, ambas devem convergir para os mesmos objetivos [2]. Assim, o conhecimento de tais necessidades e a solução de tais problemas é fundamental para a empresa JB Andaimes - locadora de equipamentos na área de construção civil, cuja atua 20 anos no mercado no Estado do Amazonas, em discernimento do grande incremento do ramo civil que alavancou a demanda por esses serviços exigindo assim, estratégias que os ajudem no gerenciamento adequado do controle do estoque da empresa. Este crescimento deve-se principalmente aos benefícios esperados e prometidos pelo valor sistemas ERP nas capacidades e recursos de informação; capital intelectual por meio de criação de conhecimento; e melhorias nas dimensões operacionais, gerenciais e estratégicos [3].

No contexto têm por finalidade averiguar a execução do sistema ERP em relação às necessidades da empresa JB Andaimes, e suas vantagens, verificando todo o encadeamento da implementação. Um sistema de controle de estoques é hoje uma ferramenta indispensável ao administrador do pequeno ou de grande negócio [4]. Podendo assim, atingir seus proventos, por meio da criação de uma cultura ERP dentro da empresa, na aquisição do programa, treinamento, consultoria e manutenção do programa. Visto que toda decisão é tomada com base em 
informações disponíveis para tal. Estas devem ser precisas e corretas, além de estarem disponíveis no momento necessário. [5].

Portanto, essa diligência teve como fim averiguar a seguinte questão: Como viabilizar a melhoria e otimização no controle do estoque? A necessidade de ter uma maneira eficaz do controle deu-se rudimento ao programa de controle de estoque, devido à situação de perda das tarefas prestadas pela entidade JB Andaimes, com a falta do sistema que possa controlar seus materiais estocados.

\section{SISTEMA DE CONTROLE DO ESTOQUE ERP}

O Enterprise Resource Planning (ERP) pode ser visto como um arranjo de programas comercial idealizado com o intuito de favorecer as distintas tarefas de uma organização por intermédio dos seguimentos de negócio. $\mathrm{O}$ papel de cada área $\mathrm{e}$ sua integração e sincronia na sequência das ações a serem desencadeadas podem ser visualizados e exercitados a partir da efetivação das escolhas estratégicas [6]. Além disto, o ERP tem como fim de associar todos os dados auferidos nesses decursos através da administração da fluidez dessa informação [7], o ERP é um sistema que facilita o fluxo de informações dentro de uma empresa, integrando as diferentes funções: manufatura, logística, finanças, recursos humanos e engenharia, entre outras.

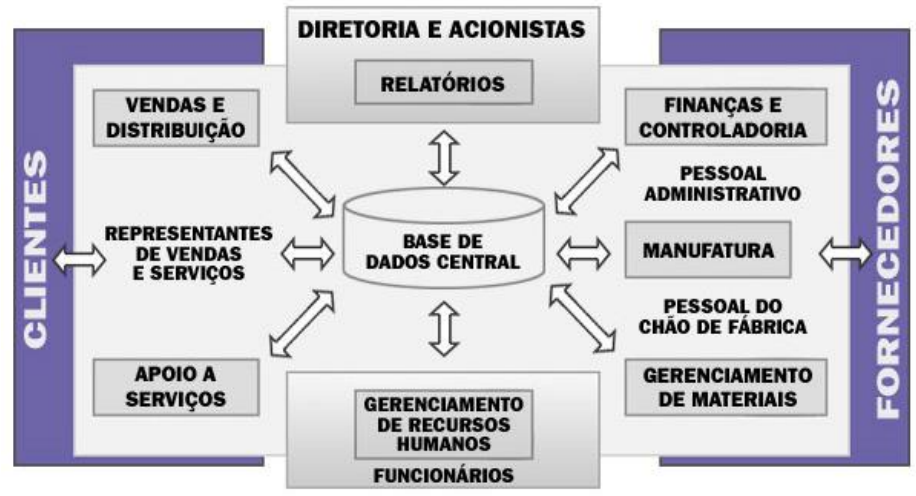

Figura 1 - Integrações do ERP.

Fonte: disponível em $<$ http:// www.ligueinfomusic.com.br/informaticaerpjp.htm >, (2014).

Conforme mostra a Figura 1, equivalente a essa assimilação entre as várias serventias que o ERP viabiliza a obtenção das informações pela conjuntura de ser um modelo integralizado, permitindo e otimizando a administração das informações, certificar-se de modo congruente dos dados e calculando de formas idênticas adequadas aos mesmos critérios em cada um dos serviços da organização.

Diante disto [8] afirma que, as atividades aglutinadas ou funções presentes em todas as organizações conferirão o fundamento para o desenvolvimento do planejamento de informações, dos sistemas de informação organizacional e dos projetos de tecnologia da informação e de software.

\section{II.1. IMPLEMENTAÇÃO DO SISTEMA ERP}

A implantação de um sistema é viável para obter proventos no uso do controle de materiais, dimensionando corretamente os estoques, reduzindo o custo e maximizando os lucros, através da projeção de um sistema tecnológico apropriado as instâncias da organização.

De acordo com [1]: Quando o objetivo principal a ser alcançado é a melhoria do desempenho da empresa e não apenas substituir um software aplicativo, implantar um sistema [...] na empresa significa modificar profundamente os métodos de trabalho em todas as suas áreas e, mais que para isso, significa modificar o comportamento de cada um dos funcionários, diante de suas atividades específicas e frente às relações funcionais com os demais participantes do processo produtivo, em toda sua extensão. De acordo com o que é demostrado na Figura 2 sobre o compasso de implantação do sistema:

\begin{tabular}{|c|c|c|}
\hline \multicolumn{3}{|c|}{$\begin{array}{l}\text { CRITÉRIOS DE DECISÃO PARA IMPLANTAÇÃO DE UM SISTEMA DE PROGRAMAÇÃODA } \\
\text { PRODUÇÃO COM CAPACIDADE FINITA }\end{array}$} \\
\hline$\swarrow$ & & 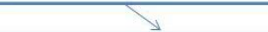 \\
\hline $\begin{array}{c}\text { NIVEIS DE INVESTIMENTO E } \\
\text { ESFORÇOS ORGANIZACIONAIS } \\
\text { EXIGIDOS }\end{array}$ & $\begin{array}{c}\text { MELHORIA DE DESEMPENHO } \\
\text { DA MANUFATURA }\end{array}$ & $\begin{array}{c}\text { MELHORIA DE DESEMPENHO } \\
\text { DA MANUFATURA }\end{array}$ \\
\hline $\begin{array}{l}\text { - Software } \\
\text { - Hardware } \\
\text { - Treinamento } \\
\text { - Implantação } \\
\text { - Manutenção do sistema } \\
\text { - Mudanças organizacionais }\end{array}$ & $\begin{array}{l}\text { - Redução em custos } \\
\text { - Aumento da velocidade de } \\
\text { entrega } \\
\text { - Melhoria na pontualidade de } \\
\text { entrega } \\
\text { - Aumento da flexibilidade de } \\
\text { volume e entrega }\end{array}$ & $\begin{array}{l}\text { - Necessidade de gestão da } \\
\text { capacidade } \\
\text { - Alinhamentoá política de } \\
\text { planejamento da produção } \\
\text { - Complexidade das decisões } \\
\text { - Funcionalidade e escopo das } \\
\text { decisões dos sistemas } \\
\text { disponíveis }\end{array}$ \\
\hline $\begin{array}{l}\text { LHA DO SISTEMA QUE } \\
\text { MELHORIA DE DESM }\end{array}$ & $\begin{array}{l}\text { ESENTAA MELHOR RELAC } \\
\text { HO vs. ADEQUAÇÃOAS NE }\end{array}$ & $\begin{array}{l}\text { VEL DE INVESTIMENTO vs. } \\
\text { ADES DA EMPRESA }\end{array}$ \\
\hline
\end{tabular}

Figura 2 - Critérios de decisão para a implantação de um sistema de programação finita.

Fonte: Corrêa, (2008).

Além disto, para se chegar um resultado desejado na implatação de um sistema MRP II/ ERP, é necessário analisar várias etapas imprecidiveis para o procedimento, ao qual se busca alcançar os resultados a ser obtidos.

Conforme mostrado no Quadro 1 classificando quais os fins de prosseguir todo esses modos de instalação de um sistema ERP para sua melhor performance.

Quadro 1- Etapas do processo de Implatação de um Sistema MRP II/ERP.

\begin{tabular}{|l|l|}
\hline \multicolumn{1}{|c|}{ Etapas } & \multicolumn{1}{|c|}{ Objetivos } \\
\hline $\begin{array}{l}\text { 1-Criação de uma } \\
\text { cultura ERP dentro } \\
\text { da empresa; }\end{array}$ & $\begin{array}{l}\text { Configurar o software para melhor } \\
\text { adequação do ambiente de negócio da } \\
\text { empresa e o comprometimento entre todas } \\
\text { as partes interessadas. }\end{array}$ \\
\hline $\begin{array}{l}\text { 2-Aquisição do do } \\
\text { Programa; }\end{array}$ & $\begin{array}{l}\text { A empresa deve avaliar qual a importncia } \\
\text { ou beneficio que esse programa oferecerá } \\
\text { adquirir esse programa, ou seja, quais os } \\
\text { problemas a ser solucionado com isso?. }\end{array}$ \\
\hline
\end{tabular}


Barbara Laenna Encarnação de Moura, et al. / ITEGAM-JETIA Vol.02, № 06, pp.84-90. Junho, 2016.

\begin{tabular}{|l|l|}
\hline & $\begin{array}{l}\text { Quais os planos e objetivos com essa } \\
\text { aquisição e qual o provedor escolhido } \\
\text { para implantar o programa, dando suporte } \\
\text { constante ao software e a empresa-cliente. }\end{array}$ \\
\hline $\begin{array}{l}\text { 3-Treinamento dos } \\
\text { usuários; }\end{array}$ & $\begin{array}{l}\text { Treinar todas as partes interessadas para } \\
\text { que todas saibam utilizar de maneira } \\
\text { correta a tecnologia que está disponivel } \\
\text { para a resolução daquele dificuldade ou } \\
\text { para a otimização do setor em evidência. }\end{array}$ \\
\hline $\begin{array}{l}\text { 4-Consultoria na } \\
\text { implementação do } \\
\text { sistema; }\end{array}$ & $\begin{array}{l}\text { Para diminuir os riscos, deve-se aplicar } \\
\text { testes, com o objetivo do melhor } \\
\text { funcionamento do programa ERP a ser } \\
\text { implantado e realizar também } \\
\text { treinamentos, esclarecendo todas as } \\
\text { eventuais dúvidas operacionais e } \\
\text { problemas da performance do programa. }\end{array}$ \\
\hline 5-Manutenção do \\
Sistema & $\begin{array}{l}\text { Manter condições adequadas para o } \\
\text { melhor funcionamento do programa, para } \\
\text { obtenção de maior resultados pela } \\
\text { empresa; Renovação contínua das versões } \\
\text { do software pelo provedor; Treinamento } \\
\text { para usuários dessa nova versão; Custos e } \\
\text { fiscalização das ações no programa e } \\
\text { apoio ao software. }\end{array}$ \\
\hline
\end{tabular}

Fonte: Autores, (2015).

Pode-se perceber ainda que a instalação de um programa ERP consegue ser muito complicado e propenso a problemas caso não esteja conforme ao ambiente da organização, por motivo das transformações instigadas. Esses riscos conseguem ser diminuído com a escolha apropriada do provedor do sistema ERP, possibilitando assim, uma boa concepção e uma administração correta. Devido às essas situações de riscos podem-se trazer vantagens e desvantagens para o meio do âmbito organizacional, como mostra no Quadro 2.

Quadro 2 - Vantagem e Desvantagem da Implantação do Sistema ERP.

\begin{tabular}{|c|c|}
\hline Vantagens & Desvantagens \\
\hline $\begin{array}{l}\text { Excluir o uso de } \\
\text { interfaces manuais; } \\
\text { Aprimorar o processo } \\
\text { da informação e a torna } \\
\text { eficiente; } \\
\text { Aprimorar o método de } \\
\text { tomada de decisão; } \\
\text { Excluir a repetição de } \\
\text { atividades; } \\
\text { Abreviar o prazo de } \\
\text { resposta ao mercado. }\end{array}$ & $\begin{array}{l}\text { Estar sujeito do fornecedor do } \\
\text { programa; } \\
\text { Adesão de práticas e uniformização } \\
\text { entre as organizações do mesmo } \\
\text { ramo; } \\
\text { Torna as partes dependentes uns dos } \\
\text { outros, pois cada setor depende das } \\
\text { informações da parte anterior, } \\
\text { devido às informações serem em } \\
\text { tempo real, ocasionando maior } \\
\text { trabalho; } \\
\text { O excedente controle sobre as } \\
\text { pessoas, o que ativa a objeção à } \\
\text { alteração e pode gerar desanimo por } \\
\text { parte dos colaboradores. }\end{array}$ \\
\hline
\end{tabular}

Fonte: Autores, (2015).
Para isso, é essencial o empenho da equipe de TI, engajamento da área de toda a organização, assistência contínua das etapas de evolução e implantação, conforme as opções mencionadas para as tomadas de decisões e de um provedor conveniente às situações da empresa, averiguação de possíveis fatores internos e externos que podem impulsionar no empreendimento, preparação de um bom princípio de garantia.

\section{MATERIAIS E MÉTODOS}

A averiguação foi feito por meio de uma visita técnica na organização para o alcance dos dados da empresa, diagnosticando vários fatores a ser solucionado, através do gráfico radar, a qual identificou como um do fator mais crítico a necessidade da empresa em gerir seus estoques de maneira prática. Apreendeu-se que a implantação de um sistema o ERP auxiliará tanto na estocagem de materiais bem como na apreensão das decisões.

Para a consecução de informações empregou-se como ferramenta perguntas abertas aos níveis estratégicos, táticos e operacionais, bem como observação direta e questionários.

Além disso, o diagnóstico qualitativo difere bastante quanto ao estado de ordenação introdutório, isto é, quanto às perspectivas que podem ser definidas já na pesquisa. Com o intuito de atender o que foi proposto foi realizado um estudo de caso. [9] define "estudo de caso" com base nas características do fenômeno em estudo e com base num conjunto de características associadas ao processo de coleta de dados e as estratégias de análise dos mesmos. Em fundamento a particularidade do caso em aplicação, foi executada entrevistas semiestruturadas com o intuito de recolher os dados de forma direta. De acordo com [10], [...] na entrevista semiestruturada, o pesquisador organiza um conjunto de questões sobre o tema que está sendo estudado, mas permite, e às vezes até incentiva, que o entrevistado fale livremente sobre assuntos que vão surgindo como desdobramentos do tema principal.

\section{ESTUDO DE CASO PROPOSTO}

A J.B Andaimes iniciou suas atividades comerciais em 1993, foi registrada na JUCEA em dezembro de 2001, tendo 20 anos no mercado de locação de equipamentos para a construção civil. Em meados de 2004 tornou-se a representante da maior locadora de andaimes do Brasil que é a MECAN. Desde o início deu prioridade a qualidade de seus produtos e na prestação dos serviços, bem como celeridade no atendimento aos seus clientes.

A empresa possui seu quadro funcional que totaliza em 39 colaboradores, que os mesmos são ajustados em conformidade com a CLT - Consolidação das Leis Trabalhistas, distribuindo-se assim em diversos cargos na organização. Ela possui um programa de contratação através de uma análise de currículos e por indicação. A contratação de funcionários é realizada através desse programa de avaliação e que possui um número maior de homens 
Barbara Laenna Encarnação de Moura, et al. / ITEGAM-JETIA Vol.02, № 06, pp.84-90. Junho, 2016.

entre seus colaboradores, o equivalente a $74,36 \%$ da quantidade total, esses dados foram recolhidos em documentos na organização.

As características do quadro funcional da J.B Andaimes estão dispostas conforme dados analisados no Gráfico 1.

Gráfico 1- Distribuição dos colaboradores de acordo com o sexo.

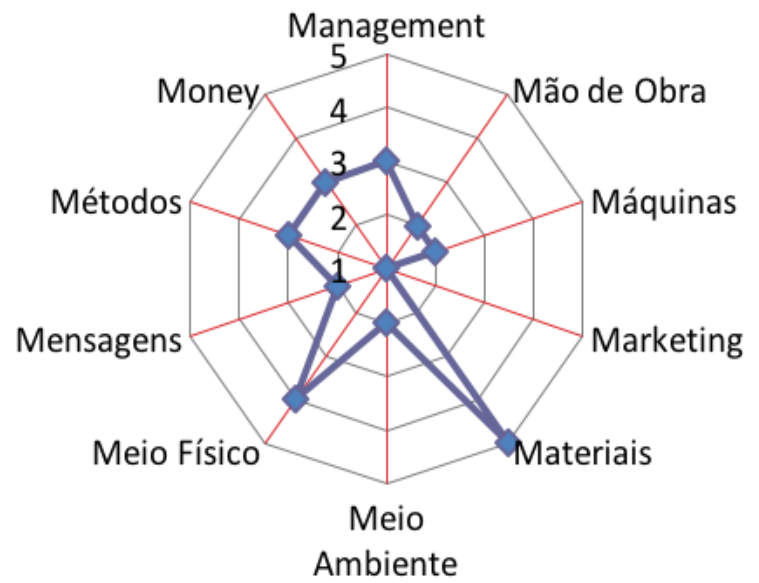

Fonte: Autores, (2015).

No Gráfico 2 é demostrado que a J.B Andaimes é composta por sua maioria de colaboradores de nível operacional, pois há um número maior de colaboradores na área de produção, indicando facilidade e rapidez no processo produtivo da organização, nos outros setores há um número menor de colaboradores, porém com pessoas capacitadas e especializadas dando um bom direcionamento ao processo. [...] Além de uma estrutura de funções especializada, a organização precisa também de uma estrutura hierárquica para dirigir as operações dos níveis que lhe estão subordinados [11].

Gráfico 2- Distribuição dos colaboradores de acordo com o nível hierárquico.

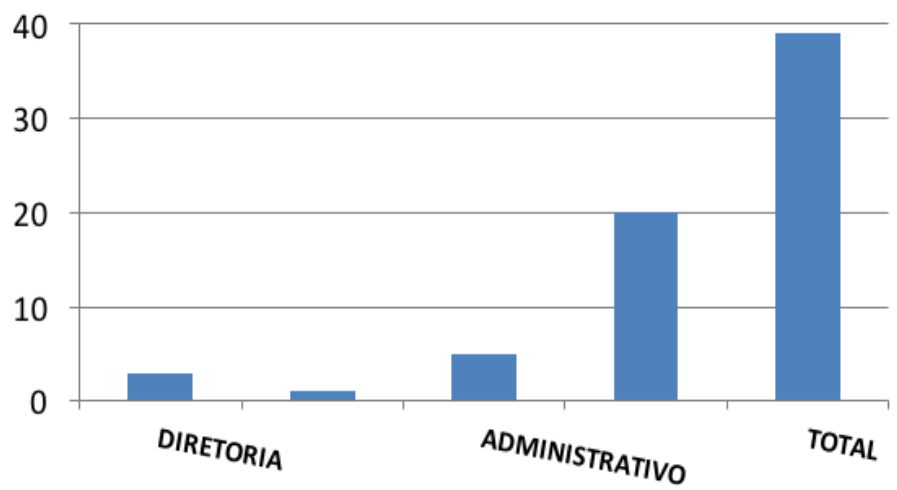

Fonte: Autores, (2016).
O serviço da J. B. Andaimes é a locação de andaimes que a empresa presta para locação em canteiro de obras, e ou locação em lugares diversos. Além da locação a empresa oferece a instalação, realizada pelos seus operários e os monitores nessa instalação caso precise de alguma manutenção imediata. No entanto ela depende dos fornecedores (fabricantes dos andaimes) para prestação de seus serviços. Os produtos oferecidos seguem normas da NR 18 e NR 35, pertencentes à MECAN, empresa líder de mercado nacional na produção de equipamentos para a construção civil, são eles: Escoras Metálicas; Andaimes tubulares; Andaimes fachadeiros.

\section{IV.1. DADOS ATUAIS DA EMPRESA}

A empresa possui um porte considerável diante ao seu faturamento anual, o porte da empresa é a classificação econômica em que a empresa está adentrada, que pode variar conforme o seu faturamento anual e/ou o número de funcionários registrados.

Através do Check List de Observação, na averiguação dos dados, verificou-se que a estrutura da empresa J.B Andaimes é um ambiente agradável e está em boas condições, sempre está acompanhada por manutenções diárias (limpeza, sistema elétrico e serviços de segurança). [12] afirma que, arranjo físico adequado proporciona para a empresa maior economia e produtividade, com base na boa disposição dos instrumentos de trabalho [...] do fator humano alocado no sistema.

Na Tabela 1 está uma apresentação do porte de empresa adotada pelo BNDES e aplicável a todos os empreendimentos. Definir o porte da empresa com adoção de critérios para definição de tamanho de empresa constitui importante fator de apoio às micros e pequenas empresas, permitindo que as firmas classificadas dentro dos limites estabelecidos possam usufruir os benefícios e incentivos previstos nas legislações que dispõem sobre o tratamento diferenciado ao segmento, e que busca alcançar objetivos prioritários de política, como o aumento das exportações, a geração de emprego e renda, a diminuição da informalidade dos pequenos negócios, entre outras [13].

Tabela 1 - Porte da Empresa.

\begin{tabular}{|c|c|}
\hline Classificação & Receita operacional bruta anual \\
\hline Microempresa & Menor ou igual a R \$ 2,4 milhões \\
\hline Pequena empresa & $\begin{array}{l}\text { Maior que } \mathrm{R} \$ 2,4 \text { milhões e menor ou igual a } \\
\mathrm{R} \$ 16 \text { milhões }\end{array}$ \\
\hline Média empresa & $\begin{array}{l}\text { Maior que } \mathrm{R} \$ 16 \text { milhões e menor ou igual a } \\
\mathrm{R} \$ 90 \text { milhões }\end{array}$ \\
\hline $\begin{array}{l}\text { Média-grande } \\
\text { empresa }\end{array}$ & $\begin{array}{l}\text { Maior que R\$ } 90 \text { milhões e menor ou igual a } \\
\mathrm{R} \$ 300 \text { milhões }\end{array}$ \\
\hline Grande empresa & Maior que $\mathrm{R} \$ 300$ milhões \\
\hline
\end{tabular}
Fonte: BNDES, (2011).

Diante a Lei Complementar 123/2006, também conhecida como lei das Micro e Pequenas Empresas faz-se a seguinte classificação apresentada na Tabela 2 . 
Barbara Laenna Encarnação de Moura, et al. / ITEGAM-JETIA Vol.02, № 06, pp.84-90. Junho, 2016.

Tabela 2 - Classificação de Micros e Pequenas Empresas

\begin{tabular}{l|ll}
\hline Segmentação & $\begin{array}{l}\text { Faturamento } \\
\text { Calendário - Ano }\end{array}$ & por \\
\hline
\end{tabular}

Micro Empreendedor Até 60 mil reais por ano

Individual Até 360 mil reais por ano

Micro Empresa De 360 mil reais a 3,6 milhões

Empresa de Pequeno de reais por ano

Porte A partir de 3,6 milhões de reais

Grande Empresa por ano

Fonte: SEBRAE, (2013).

O porte da empresa permite com que a própria empresa usufrua de benefícios e isenções de tributos conforme as principais legislações vigentes. Ela se desenvolve e adquire financiamentos e apoios mais facilitados, pois é levado em conta o seu rendimento, de acordo com sua classificação. Adquirem mais facilidades e prazos, bens para a empresa e pode adquirir mais funcionários, mas proporcional ao seu faturamento são suas obrigações. Na ocasião em que uma empresa se aperfeiçoar e adquire permanência no mercado, ela acaba auferida mais notoriedade, consequentemente mais clientes, então chega o momento em que é necessário fazer uma mudança em seu ambiente físico, analisar o seu espaço geográfico, seu layout interno e suas instalações.

Para [14] conceitua instalações físicas a arrumação do espaço, máquinas, equipamentos e materiais em um escritório, loja ou fábrica com o objetivo de manter a maior produtividade possível. Com sustentação nessa informação a empresa JB tem instalações físicas bem estruturadas, onde são divididos os cômodos da empresa de acordo com cada departamento da empresa, onde funciona seu escritório dispõe de um amplo espaço físico de $372,21 \mathrm{~m}^{2}$ que funciona a área administrativa. Há uma divisão do layout interno da empresa, de forma que o galpão, onde ficam armazenados os andaimes, está em um lugar adequado e separado do setor administrativo.

Com relação ao faturamento anual da empresa JB Andaimes, de acordo com análise documental é de R \$3.200,00 (três milhões e duzentos reais), levando-se em conta o enquadramento das empresas de acordo com seu faturamento e número de funcionários registrados. A JB Andaimes pode ser então considerada uma Empresa de Pequeno Porte, obtendo uma receita bruta anual de ate 3,6 milhões (três milhões e seiscentos reais).

Conforme pesquisas realizadas através de questionários e análise dos processos e informações fornecidas pela organização foram possíveis identificar vários problemas almejando alcançar soluções. Observando o gráfico de análise crítica, os atributos estão divididos em três categorias: pontos fortes, pontos a melhorar e pontos fracos.

\section{IV.2. GRÁFICO RADAR DE ANÁLISE CRITICA}

O gráfico-radar tem como finalidade demonstrar as áreas críticas de uma organização de maneira integrada e global como afirma [15] o gráfico-radar é uma forma clara e pictórica de representar o resultado da análise de cada uma das dez áreas mencionadas, $[\ldots]$ construído de forma circular, espalhando-se de forma radial, as dez áreas mencionadas. A partir do embasamento teórico, é de suma importância que toda empresa faça seu autodiagnostico para identificar problemas, os quais interferem no progresso da instituição.

De acordo com o gráfico da Figura 3, o atributo Materiais encontra-se na Zona 5 e indica uma grande deficiência da empresa, a qual não possui em seu controle interno meios de adquirir informações sobre seus estoques de andaimes, além disso, não há um processo de registro de peças fornecidas, em manutenção e em estoque, ficando apenas anotado quantas peças foram locadas.

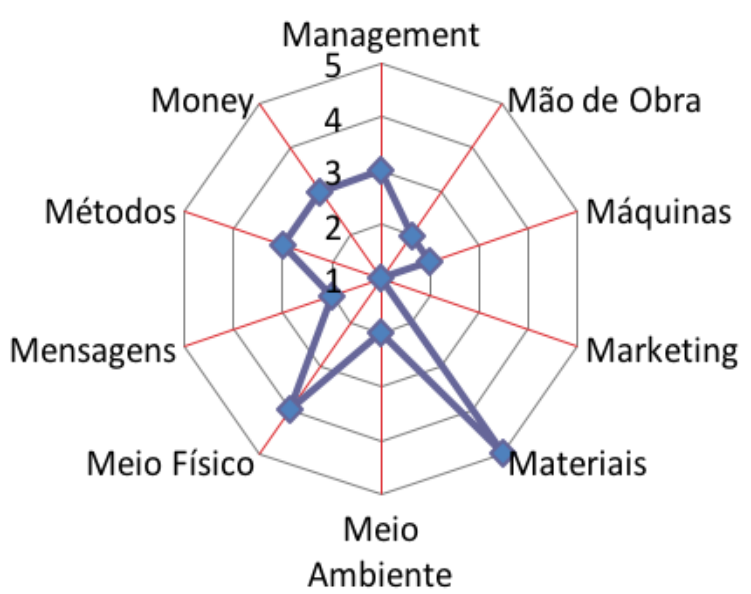

Figura 3 - Gráfico Radar da Análise Crítica.

Fonte: Autores, (2015).

Seus funcionários não gozam de uma capacitação mais avançada sobre um sistema de controle de estoque, ficando assim, essa parte a desejar. Uma vez, que o controle determina com mais especificidade, os valores monetários relacionados ao faturamento da empresa, seus custos e suas despesas, relacionadas com a manutenção dessas peças, permitindo a empresa terem controle do faturamento global e adquirindo a lucratividade almejada.

Portanto, recomenda-se que a instituição continue oferecendo produtos e prestando serviços de qualidade com mesma determinação, e por isso ela deve investir mais em novas tecnologias e desenvolvimentos de seus colaboradores na satisfação dos seus clientes/acionistas e adequando-se ao mercado de forma continua contribuindo assim para o sucesso da mesma, satisfazendo as necessidades de todos os envolvidos. Por isso a organização deve estar em constante mudança.

\section{IV.3. RESULTADO E DISCUSSÕES}

Após a sugestão para maior percepção dos resultados alcançados com a implantação do Sistema de Controle de Estoque ERP, segue abaixo um quadro demonstrativo comparando o antes e depois da implantação do Sistema no Quadro 3, onde foram $88-$ 
Barbara Laenna Encarnação de Moura, et al. / ITEGAM-JETIA Vol.02, Nº6, pp.84-90. Junho, 2016.

observados os processos realizados antes da implantação do Sistema de Estoque que a empresa JB Andaimes fazia e as mudanças ocorridas após a implantação do Sistema de Controle de Estoques:

Quadro 3 - Processo do resultado da implantação do Sistema de Controle de Estoque.

\begin{tabular}{|c|cc|}
\multicolumn{2}{c|}{ Antes } & \multicolumn{2}{|c|}{ Depois } \\
\hline Recebimento de & $\mathrm{O}$ produto é identificado por
\end{tabular}

Materiais: apenas por códigos no sistema que permite nota fiscal; saber dados do material. $\mathrm{Na}$ compra é atualizado no sistema de entradas e os valores pagos e recebidos.

Dados da locação: Através do Sistema ERP é através de nota de permitido saber a quantidade, os serviço. prazos e o locatário são cadastrados no sistema.

Cadastro de peças através do Dados dos produtos: Sistema de Controle com dados, anotação em planilha de compra em Excel. características, peças de manutenção, possibilidade de emissão de relatório.

Quantidade de estoque: Acesso à quantidade de peças contagem manual do disponível, peças em manutenção, estoque através do e peças locadas através do Sistema.

responsável em cada solicitação de serviço.

Serviços de Pedidos: anotados em nota de serviço/digitados através do atendimento por telefone.

Fonte: Autores, (2015).

Diante disto, com o sistema implantado foi possível obter as informações dos registros de locação tendo o controle sobre o estoque e estabelecendo assim, para cada produto acessório de montagem ou modelo de andaime, um estoque mínimo demonstrado na Tabela 3:

Tabela 3 - Controle de Estoque

\section{Estoque Mínimo de Andaimes}

\begin{tabular}{l|c}
\multicolumn{2}{c}{ Estoque Mínimo de Andaimes } \\
\hline Produtos & Quantidade $\left(\mathbf{M}^{\mathbf{2}}\right)$ \\
\hline Andaimes Fachadeiros & 15.245 \\
Andaime 1,5 Mecanfix & 4.500 \\
Andaime 1,30 & 2.000 \\
Andaime 1 x 1,50 & 2.000 \\
Andaime 1 x 1,30 industrial & 2.500 \\
Andaime Tubolar & 2.200 \\
\hline
\end{tabular}

As informações averiguadas mostraram que um sistema implantado com o suporte adequado, com treinamento de seus colaboradores envolvidos, ofereceu uma redução de tempo, de custos e agilidade de ações decisórias e corretas que se realizaram com mais frequência. Antes, não se tinha total conhecimento da quantidade de peças faziam parte do estoque e em diversas situações a contagem manual aumentava o tempo de espera do cliente e aumentava a incerteza dos dados gerados. Outro detalhe interessante, o sistema gerou a possibilidade de fazer reposições no estoque devido à depreciação das peças pelo uso nas locações. Concedendo uma melhoria consecutiva e manutenções preventivas nas peças, evitando transtornos e/ou descontinuidades dos serviços por imprevistos concernentes à qualidade dos materiais (andaimes).

A maior dificuldade para a implantação do sistema é comprovar que sua existência na empresa gera otimização nos decursos operacionais e decisórios facilitando a capacidade de desenvolver-se mais, devido aceitação e a flexibilidade dos proprietários para a sua devida implantação na empresa. [16] argumentam que as organizações poderiam alavancar sistemas integrados para alcançar melhores operações e melhor controle de custo e outros recursos, em última análise, levando a melhorias de desempenho organizacional.

\section{CONCLUSÕES}

A pesquisa atual tem como fim a otimização dos serviços na empresa JB Andaimes, com a implantação de um sistema de informação ERP, facilitando o controle de todos os seguimentos, principalmente o total domínio sobre o número de peças para locação e a quantidade restante para futuros serviços, na melhoria da gestão do controle de seus materiais, tendo maior destreza para o alcance das informações sobre seus produtos, agilizando o sistema operacional de controle logístico, podendo assim cumprir com os prazos preestabelecidos.

O desenvolvimento gradativo da logística em várias companhias com implantação do sistema ERP tem cooperado abundantemente para as tomadas de decisões na obtenção dos resultados a ser atingido, como estratégia no mercado competitivo. Devido à praticidade que esse sistema oferece à organização, levando em conta a agilidade da informação em momento exato de um fechamento de serviço com um cliente, abatendo os custos, diminuído a demora no atendimento aos serviços e abreviando a possibilidade de erros de informação relacionados ao número de peças disponíveis, sua implantação oferece um melhor custo/benefício para a empresa que souber treinar e capacitar seus funcionários a ter contato com o sistema, tornando-o viável. Colaborando assim, para o fechamento financeiro mensal, nas tomadas de decisões geradas no momento de inúmeras transações de negócios efetuadas com os clientes da empresa. Assegurando um acréscimo significativo a empresa no seu faturamento anual.

\section{AGRADECIMENTOS}

Ao Centro Universitário do Norte (UNINORTE) e a Empresa JB Andaimes, pelo apoio a realização desta pesquisa. 
Barbara Laenna Encarnação de Moura, et al. / ITEGAM-JETIA Vol.02, No 06, pp.84-90. Junho, 2016.

\section{REFERÊNCIAS BIBLIOGRÁFICAS}

[1] CORRÊA, Henrique Luiz. GIANESI Irineu Gustavo Nogueira. CAON, Mauro. Planejamento Programação e Controle da Produção - MRPII/ ERP Conceitos, Usos e Implantação: base para SAP, Oracle Applications e outros software integrados de gestão. $5^{a}$ ed. - 2. reimpr. - São Paulo: Atlas, 2008, p.17, p.400.

[2] CHOPRA, S.; MEINDL, P. Gerenciamento da Cadeia de Suprimentos: Estratégia, planejamento e operação. - São Paulo: Prantice Hall, 2003.

[3] MOLlA. A. BHALlA. A. ERP e Vantagem Competitiva em Países em Desenvolvimento: o caso de uma empresa asiática Electron. J. Inf. Syst. Dev. Países, 2006.

[4] LACERDA, Leonardo. CEL - Centro de Estudos em Logística - COPPEAD/UFRJ. Instituto de Pós-Graduação em Administração da UFRJ. Artigo automação na armazenagem: desenvolvendo e implementando projetos de sucesso, 2005.

[5] FAVARETTO, Fábio; CUNHA, Nara Inês Pereira Vieira; ORMEROD, Paulo Ernesto Seabra Bueno. Implantação de sistema de suporte à decisão para gerenciamento de índices de refugo. Simpósio de Engenharia de Produção - X SIMPEP. 10 a 12 de novembro de 2003.

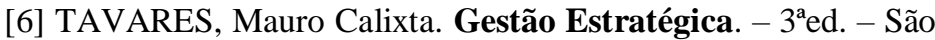
Paulo: Atlas, 2010, p.258.

[7] MARTINS, Petrônio Garcia. LAUGENI, Fernando Piero. Administração da Produção Fácil. - São Paulo: Saraiva, 2012, p. 150

[8] REZENDE, Denis Alcides. Engenharia de software e sistemas de informação. 3 ed. rev. e ampl. Rio de Janeiro: Brasport, 2005, p.316.

[9] YIN, R. K. Estudo de caso - Planejamento e Métodos. $3^{\mathrm{a} e d .}$ - Porto Alegre: Bookman, 2010.

[10] PÁDUA, Elisabete Matalho Marchesini de. Metodologia da pesquisa: abordagem teórico - prática. 10 ed. Ver. E atual. Campinas, São Paulo: Papirus, 2008, p.70.

[11] CHIAVENATO, Idalberto. Introdução à Teoria Geral da Administração: uma visão abrangente da moderna administração das organizações. $8^{\text {a }}$.ed.Rio de Janeiro: Elsevier, 2011, p. 158 .

[12] OLIVEIRA, Djalma de Pinho Rebouças de. Planejamento Estratégico: Conceitos, metodologias e práticas. $-31^{\circ}$. ed. São Paulo: Atlas, 2013, p.364.

[13] SERVIÇO BRASILEIRO DE APOIO ÀS MICRO E PEQUENAS EMPRESAS (SEBRAE). Anuário do Trabalho na Micro e Pequena Empresa 2009. Brasília/DF, 2010, p.13.
[14] LACOMBE, Francisco José Masset. Dicionário de administração. São Paulo: Saraiva 2004.

[15] COSTA, Eliezer Arantes da. Gestão Estratégica: da empresa que temos para empresa que queremos. $-2^{\circ}$. ed.- São Paulo: Saraiva, 2007.

[16] CHAPMAN, C. S. KIHN L.A. Integração de sistemas de informação: permitindo o controle e o desempenho Conta. Órgão. Soc., 34 (2009), p. 151-169.

[17] MENDES, Juliana V.; ESCRIVÃO, Edmundo F. Sistemas integrados de gestão ERP em pequenas empresas: um Confronto entre o Referencial Teórico e a Prática Empresarial. Gestão \& Produção, v. 9, n. 3, 2002, p.277 - 296.

[18] MORAES, Natacha. Seleção de sistemas de gestão e o impacto no processo de implantação: Um estudo de casos múltiplos. Dissertação (Análise de Sistemas do Centro de Ciências Exatas e Tecnológicas) - Universidade do Vale do Rio dos Sinos, São Leopoldo, 2003. 